\title{
The Excitement of Crossing Boundaries
}

\author{
DAVID B. WONG \\ Duke University, North Carolina, USA (d.wong@duke.edu)
}

This is an intellectual autobiography that aims to explain how I am both an analytic philosopher who writes on questions of moral relativism and pluralism and also on classical Confucianism and Daoism. I have written on the subjects of moral psychology and moral epistemology, articulating what I see to be a fruitful consilience between insights of both Confucian and Daoist thinkers and some of the latest findings in psychology and neuroscience. I regard as synergistic and completely logical this combination of interests, but many find it surprising, so I identify the experiences and influences that brought me to where I am now.

Keywords: meta-ethics; ethics; Chinese philosophy; Confucianism; Daoism; moral psychology; moral relativism

I am a philosopher trained in the American analytic tradition. I have defended a naturalistic theory of morality as a cultural invention. A naturalistic theory in my sense is informed by, though not reducible to, the most relevant scientific theories that pertain to explaining what sort of thing morality is. I deny that morality is part of the original fabric of the world but hold instead that it is constructed as part of culture to structure cooperation and to impart coherence to the potentially conflicting and diverse impulses in the human psychological economy. On questions of relativism versus universalism in morality, I have argued that there is no single true morality, and also that there are constraints on what can be a true morality. I am also a philosopher who works in the early Chinese philosophical traditions, primarily Confucianism and Daoism. In more recent years, I have ventured into the subjects of moral psychology and moral epistemology, articulating what I see to be a fruitful consilience between insights of both Confucian and Daoist thinkers and some of the latest findings in psychology and neuroscience. I regard as synergistic and completely logical this combination of interests. Yet it is not unusual for people to say that they know of or have read my work in ethical theory but not my work in Chinese philosophy, or vice versa, as if I would have to have freakishly long legs to have one foot in each camp. So perhaps there is some general interest in how my feet got planted.

I grew up Chinese American, in the first generation to be born in the U.S., in Minnesota. There weren't that many Chinese or Chinese Americans in Minneapolis, so I experienced not simply being a minority, but also being an oddity, someone who would elicit incredulous stares just by walking down the street. My interest in matters of cultural difference began with the difference between the ways of my family and the ways of almost everyone else around us. Like many children of immigrants, I could not even explain to my parents what my major was in college, yet I could not have gotten to where I am now were it not for their unwavering support.

When I was attending Macalester College, the person who most inspired me to study philosophy was Thomas Hill, Sr. I admired the lucidity of both his teaching and writing, the sympathetic way he presented the motivations for each theory, often wildly different from and conflicting with each other, and the way he put together his critique of each theory into his own persuasive synthesis on the subject at hand. Perhaps most of all, I admired the way he embodied and

Journal of World Philosophies 2 (Summer 2017): 149-155

Copyright @ 2017 David Wong.

e-ISSN: 2474-1795 • http://scholarworks.iu.edu/iupjournals/index.php/jwp• doi: 10.2979/jourworlphil.2.1.11 
personified his way of doing philosophy. He was a patient, kind person who would listen to his students to find what was worthwhile in what they said, even if it sounded entirely wrongheaded to the rest of us. He would sometimes weave into his discussions of ethics his experiences in taking a stand for civil rights in the South and against the denial of voting rights to African Americans and their systematic and legally enforced segregation and oppression.

At Macalester, I was a full-on objectivist and universalist (holding that there is a single true morality) in ethics, but at Princeton became sympathetic to moral relativism. No doubt one of the reasons was Gilbert Harman's influential work on relativism. My path to that view was not the same as Harman's, but he made it safer, if not entirely so, to challenge the orthodox dismissal of relativism. More generally, I absorbed a Quinean naturalistic approach to epistemology and the philosophy of language that made no sharp separation between philosophical and scientific activity. The naturalistic view of morality I came to adopt, particularly one that saw its origin as having a lot to do with enabling and structuring social cooperation, made there being no single true morality a reasonable possibility, given the likelihood that there is no single best way for human beings to cooperate. I was also becoming persuaded, partly through reading Thomas Nagel (not that he would fully agree with the relativist conclusions I drew) that there are no persuasive resolutions to many important and fundamental disagreements, such as those between deontologists who thought that some things can never be done to a person no matter how good the overall results and consequentialists who thought that any means is in principle justified if the results are good enough.

In the two or three years it took to my write my dissertation, I had moved away from Princeton to continue a romantic relationship that ultimately failed. During that time, I decided to live in Ann Arbor where my friend Louis Loeb was teaching philosophy at the University of Michigan. It was in Ann Arbor that I met the woman who was to become my wife, Laura Weisberg. She transformed my life and opened me up to a world in which marginality was no longer the dominant feeling. I can only say how fortunate and grateful I am for the life-sustaining love and laughter she made possible, and for, among other things, introducing me to theories from her own field of psychology that in the future would deepen my interests in moral psychology and feed into my appreciation of Confucian and Daoist insights into the process of self-cultivation. During this time, I also worked at a bookstore while writing my dissertation. Being in the midst of all those books opened up my intellectual curiosity again, after an inevitable narrowing and focusing of my interests at Princeton. It was a pleasure to see simply where my interests led me, to which books I was moved to open. Among other things, I gravitated toward Chinese philosophy. Books on East Asian poetry and landscape painting led me to Buddhist and Daoist works such as the Daodejing and Zhuangzi, and that led me to the Confucian texts they were in dialectical conversation with, the Analects and Mencius, and I began to see Chinese philosophy in a new light as fruits of a sensibility that could inform one's relationships with other people and nature.

My work on relativism (including articles and two books) has spanned the length of my career to date. The approach of my first book, Moral Relativity, reflects the philosophy of language I learned at Princeton. I situated my argument that there is no single true morality within the framework of asking what makes for the best translation of different moral languages, where a translation specifies the conditions under which moral judgments are true. I argued that the best translation makes for the best explanation of people's linguistic and nonlinguistic behavior. The first book, ${ }^{1}$ and to an even greater extent, my second book, ${ }^{2}$ not only reflects my training in analytic philosophy but also my reaction to its narrowness and rigidity in the way it approached the problems that concerned me. 
For example, the type of relativism usually considered and quickly dispatched in the analytic literature is the crudest form possible, e.g., that all moralities or moral positions are equally justified or true, that a person's thinking something is morally right makes it right for that person, or that the group' or society's moral standards set what is morally right for its members. To be sure, laypeople sometimes formulate moral relativism in such terms, but typically no sympathetic examination of the legitimate motivations for such views is undertaken, and no attempt is made to formulate a more plausible version that answers to such motivations. The strawman is then juxtaposed to some form of universalism as the either/or choice. No effort is expended to show that there are only two choices.

Both books on relativism also attempt to remedy the glaring omission in almost all discussions of moral relativism, either pro or con, of substantive and sustained discussion of the moral traditions of other cultures. ${ }^{3}$ When cases of cultural differences in moral values are discussed at all, and they usually aren't, the usual way was to cite these cases as illustrations of theses that had already been derived through conceptual analysis and linguistic intuition. One of the primary questions addressed by philosophers working on this topic is, "What is the best explanation of major value differences, and what are the implications of that explanation for the question of whether there is a single true morality?" Universalists give stock explanations of why there is disagreement: many parties to moral disagreements do not reason carefully enough; they find it hard, or do not want, to imagine what it is like to occupy someone else's position; their interests wrongly influence their beliefs. And perhaps, there are cases of moral disagreement in which there really is no fact of the matter as to who is right, i.e., what is right on the issue in dispute is simply indeterminate. ${ }^{4}$ To point out the possibility of these explanations is usually taken to be a sufficient argument against relativism. What I did not and still do not see is a serious and sustained attempt to validate any of these stock explanations as applied to any particular major cultural value difference. Universalists merely assume that they apply, as if they had an entitlement to do so.

My dissatisfaction with the prevailing state of meta-ethics led me to identify major conflicts between values that resonate across cultures and accordingly present an opportunity to see how people of different times and places approached these conflicts. I have discussed conflicts between the duties of personal relationship that might involve gratitude for what one has received from another versus duties we owe to every human being and especially to those in severe need; conflicts between individual rights versus promoting the greatest good for all affected; and conflicts between the value of community and relationships on the one hand and of personal autonomy (freedom to choose how to live one's live) and individual rights on the other hand. I thought that something important would be gained in ethical theory by exploring major value differences with patience and openness to being surprised.

My framing of these value conflicts in Moral Relativity was highly influenced by the way Alasdair MacIntyre ranged over the history of Western philosophy to compare traditions of thought centered on the good for human beings, virtues, and practices on the one hand, and liberal traditions centered on the value of autonomy and rights on the other hand. My reading in Chinese philosophy led me to see the parallels (as well as the differences) between Confucianism in particular and virtuecentered traditions starting in ancient Greece. I incorporated these comparisons into my argument that the best explanation of the moral discourse and practice of societies with virtue-centered traditions and rights-centered traditions leads to the conclusion that such societies have different truth conditions for their moral judgments.

My thinking about relativism evolved in a number of different ways that culminated in my second book, Natural Moralities: A Defense of Pluralistic Relativism. I shall here highlight the role of a 
phenomenon I call "moral ambivalence." Moral differences, even across cultural traditions seen to be widely different, often involve differences in how people interpret or prioritize common values. I have argued that such differences over how to resolve conflicts between values prompt in at least some of us (not just philosophers), the experience of "moral ambivalence." One may recognize both values in conflict as genuine and important to human beings, but experience ambivalence when reflecting on which priority ranking to be accorded. We see that reasonable and knowledgeable people could have made different decisions, and any prior convictions we might have had about the superiority of our own decisions get shaken. The value conflicts I have mentioned all have created ambivalence for me, but the conflict between values of individual rights and relationships has been the one that I have felt most personally and goes back to my experience growing up in Minnesota.

My argument is that the best explanation of such ambivalence is not that morality has the true and single answer to conflicts of values, but that it is a cultural invention that addresses the need of human beings to structure the lives they live together, and also structure their array of potentially conflicting motivations, which are self-regarding, other-regarding, and everything in between. Because morality must address these needs for interpersonal and intrapersonal coordination, and because human beings have a typical array of motivations, there are limits on what kind of morality could be an adequate one for human beings. For example, I think that all moralities adequately serving the function of fostering social cooperation must contain a norm of reciprocity-a norm of returning good for good received. Such a norm is a necessity, I argue, because it helps to relieve the psychological burden of contributing to social cooperation when it comes into conflict with selfinterest. Different moralities are distinguished by the particular values they give a central place to, and by how they interpret these values. Because there are constraints on what could adequately serve the functions of morality, not all such moralities will be true. But a range of moralities will satisfy the constraints. This is how I arrive at the position that there is no single true morality but that not all moralities are true.

This "pluralistic relativism" has led me to discuss how adherents to different moralities can learn from each other, especially since they are likely to share values. For example, I have argued that all adequate moralities must have the value of accommodation, which requires one to strive to maintain constructive relationships to those with whom one has difficult moral disagreements. Even within relatively cohesive moral communities, upholding accommodation is needed as a way of preserving cooperative bonds with others as one tries to cope with the disagreements one has with them. Confucianism is an ethic centered on the value of preserving relationship with others, and in this regard it has resources that anyone in other moral traditions has reason to learn from. Normative ethics, in my view, has focused too much on showing one kind of normative theory to be the correct one, whether it be deontology, consequentialism, or virtue ethics, and has not focused on the problem of how to act ethically toward those who will not agree with many of one's fundamental moral premises.

The theoretical focus of my second book on morality as a way of fostering social cooperation for creatures with a characteristic psychology also led me to conclude that all adequate moralities, despite their legitimate value differences, need to foster moral agency, with an especially crucial component of such agency being the capacity to act competently on concern for others. All adequate moralities must have the norms that conduce to the nurturing of such agency. My research on the relevant psychological science led to make the argument that relationships of the right sort are crucial, even for moralities very much focused on the values of personal autonomy and individual rights. 
When teaching at Brandeis University (1976-2000), I belonged to a study group that had its center of gravity in moral psychology, especially as it intersected with virtue ethics, moral and political philosophy, multiculturalism and race. Colleagues in that group who especially influenced me were Lawrence Blum, Owen Flanagan, and Amélie Rorty. Their widely ranging interdisciplinary interests in psychology, sociology, history, and literature, which resulted in a remarkably diverse set of readings for the group, opened up for me the possibility of doing philosophy as an "omnivore," taking everything that was nourishing and vital to one's thinking about a subject wherever it was to be found. Many of these readings got incorporated into my work from the period of my participation in the group and forward to the present moment.

My interests in ethical theory and relativism in particular motivated my entry into Chinese philosophy, but once there, I realized how worthwhile the destination was for its own sake. Confucianism has brought home to me in an increasingly vivid and compelling way that a worthwhile life is one of relationship. The work of David Nivison made it clear how much early Chinese philosophy could be brought into fruitful dialogue with problems in moral psychology that were framed in the language of analytic philosophy. At the same time, work from Roger Ames, David Hall and Henry Rosemont, Jr. presented Chinese philosophy as offering much needed alternative thinking on ways to conceive of personhood or human rights. Kwong-loi Shun in Chinese ethics and Joseph Chan in political philosophy were producing exciting work in an analytic mode that stimulated my own thought in those areas.

My move to Duke University in 2000 brought with it not only the opportunity to teach graduate students but also colleagues, including Owen Flanagan, who were highly interdisciplinary in the way they did philosophy. The Zeitgeist they formed helped me to explore the ways some of the most interesting developmental, cognitive, and social psychology, along with the developing neuroscience, has resonated with the moral psychology of the Chinese masters. For example, some of the most intriguing science has pointed to alternative conceptions of the relation between reason on the one hand and desire and emotion on the other hand. ${ }^{5}$ In Western traditions of philosophy, these two sides have been separated with one being subordinated to the other. The moral psychology of Mencius is more in line with the developing science in revealing how reflection, reasoning, desire and emotion intersect and interact with one another. Furthermore, studying Confucius, Mencius, and Xunzi have impressed upon me the way we form ourselves in particular social and cultural environments and in our relationships with one another. Here again, debates in psychology as to the relative influence of situation versus character dispositions of the agent show how vital the issue is.

My interests in Daoist texts, especially the Zhuang₹i, have also intersected with my interests in ethical and moral psychology and epistemology. I read the Zbuangzi as expressing an epistemic humility and constructive skepticism with regard to human theories of what value and duty, especially those that impose orderly patterns of value hierarchies onto the messiness of lived experience. At the same time, I find that Zhuangian skepticism is nondogmatic, as demonstrated by its questioning of any claims to know, including definitive claims to know that we don't know. The point of Zhuangian constructive skepticism is to undermine encrusted "knowledge" that occludes what doesn't fit with it but is waiting there to be discovered, and this applies to values and ways of interpreting values that are occluded by what we already think we know.

This constructive skepticism suggests a far more positive attitude toward moral difference and disagreement than is usually adopted, and I have incorporated it into my writings on the ethics of disagreement. Instead of merely tolerating others with whom one disagrees, one might instead adopt the attitude that they might value things one has not adequately appreciated. This requires neither a suspension of one's previous commitments nor "going over" to the other side. One might have a 
better sense of the trade-offs involved in adopting any definite commitment; or one might revise one's original commitment so as to incorporate in some respects but perhaps not others the insights one has gleaned from others.

I have also gained from Zhuangzi an appreciation for embodied, intuitive ways of learning about the world, which is connected to the need to "empty" one's mind of preconceptions about what one thinks one knows already. This of course is suggested by the famous "skill" stories such as the butcher who is able to skillfully navigate his knife through the hollows and spaces of an ox, not with his eyes, not with his mind, but seemingly as a spirit who is able to roam about in the hollows and spaces. Most recently I have been exploring the ways this conception of intuitive exploration of the world can be put into dialogue with the most recent science on the manner in which most of our learning about the world takes place on a nonconscious level where we take in recurring patterns in our experience and store them in long-term memory. Some of these patterns are too complex and occur in such a brief interval of time for the conscious mind to register them. Yet they have shown to be able to guide our behavior. The relevant Chinese texts, both Confucian and Daoist, have led me to appreciate how the attentive conscious mind can come to appreciate and even to foster and to regulate the learning that takes place in these nonconscious depths.

Chinese philosophy afforded me the opportunity to reconnect in new ways with the original motivation I had for getting into philosophy in the first place: the desire to grapple with and make sense of life experiences that shape who I am, for example, how interactions with key people, some of them mentioned here, changed my life's course. Chinese philosophy is highly unusual for the degree to which it holds itself accountable to such life experience. The Analects can be read as a record of how Confucius and his students helped each other in their projects of self-cultivation, and in fact how those projects are collaborations in which they support, challenge, advise and test each other. The Mencius and Xunzi contain deep insights into bow others can help shape us.

This is not to underestimate the difficulty of trying to present a clear and rigorous understanding of matters that are often indirectly and metaphorically articulated, sometimes more shown than directly described, and even when described the content may be intended to be addressed to the particular person who is the audience depicted in the text and not to the general reader (this often seems true of the Analects, or example), but believe that analytic philosophy can take on its greatest value when charged with illuminating such matters and not merely with responding to the latest controversy that only professional philosophers can understand or take an interest in. One constant that has fueled my thinking and writing in philosophy is the excitement of crossing boundaries, whether they are culturally defined boundaries between traditions of philosophy or disciplinary boundaries between philosophy, history, literature and the sciences. The other constant is my agreement with the Chinese tradition that philosophy must be accountable to the life experience of us all.

David Wong is Susan Fox Beischer and George D. Beischer Professor of Philosophy at Duke University, North Carolina, USA. His monographs are: Natural Moralities (Oxford: Oxford etc., 2006) and Moral Relativity (Oakland, California: University of California Press, 1984). Wong co-edited the volume Confucian Etbics: A Comparative Study of Self, Autonomy and Community (New York: Cambridge University Press, 2004) with Kwong-loi Shun. For some of his recent publications, see: "On Learning What Happiness Is," Philosophical Topics: Special Issue on Happiness 41, no. 1, (2013): 81-101; "Integrating Philosophy with Anthropology in an Approach to Morality," Anthropological Theory 14, no. 3, (2014): 336-55; “Chinese Philosophy: The Beginnings of Morality," Philosopher's Magazine 65, no. 2, (2014): 76-83; "Early Confucian Philosophy and the Development of Compassion," Dao 14, 
no. 2, (2015): 157-94; "Responses to Commentators," Dao 14, no. 2, (2015): 225-33; “Growing Virtue: The Theory and Science of Developing Compassion from a Mencian Perspective," in The Philosophical Challenge from China, ed. Brian Bruya (Cambridge Mass.: MIT Press, 2015), 23-58.

$1 \quad$ Moral Relativity (Berkeley, CA: University of California Press, 1984).

2 Natural Moralities: A Defense of Pluralistic Relativism (New York: Oxford University Press, 2006).

3 Notable exceptions were Richard Brandt, Hopi Ethics (Chicago: University of Chicago Press, 1954), and John Ladd, The Structure of a Moral Code: Navajo Ethics (Cambridge, MA: 1957).

$4 \quad$ For example, such explanations are given by David Enoch, 'How is Moral Disagreement a Problem for Realism?' Journal of Ethics 13 (2009): 15-50; and by David Brink, Moral Realism and the Foundations of Ethics (Cambridge: Cambridge University Press, 1989), 197-209.

$5 \quad$ Examples include Antonio Damasio's work on the embodied and affective nature of reasoning in Descartes' Error: Emotion, Reason, and the Human Brain (New York: Putnam, 1994; revised Penguin edition, 2005) and The Feeling of What Happens: Body and Emotion in the Making of Consciousness (New York: Harcourt, 1999). 